be more prevalent in Bogotá $(2,8 \%, 95 \% \mathrm{Cl}, 1,8 \%-4,1 \%)$, Cali $(4,2 \%, 95 \% \mathrm{Cl}$, $2,4-7,3 \%)$ and Barranquilla (1,5\%, 95\% Cl, 0,65-3,23\%). Table 1.

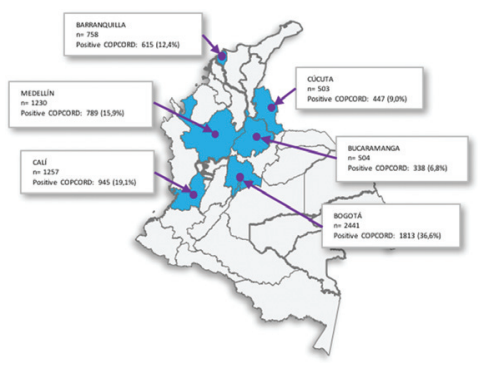

Abstract AB1298 - Figure 1. Diagram of cities surveyed as COPCORD* positive

COPCORD*: Community Oriented Program for Control of Rheumatic Diseases Conclusions: Prevalence of rheumatic diseases is higher in the cities of Bogotá, Cali and Medellin. In Bogotá, Cali and Barranquilla, RA was more prevalent. Low back pain was found to be more prevalent in Barranquilla. The hypothesis is that ethnic diversity of Colombia could explain the difference in prevalence of the rheumatic disease among separate regions.

Disclosure of Interest: None declared

DOI: 10.1136/annrheumdis-2018-eular.4356

\section{AB1299 FUNCTIONAL CAPACITY MEASURED BY HAQ IN PATIENTS WITH RHEUMATIC DISEASES IN COLOMBIA}

F.M. Cuervo ${ }^{1}$, A. Santos ${ }^{1}$, E.L. Saldarriaga ${ }^{1}$, J.C. Rueda ${ }^{1}$, I. Angarita ${ }^{1}$, J. Ballesteros ${ }^{1}$, I. Peláez ${ }^{2}$, E. Forero ${ }^{3}$, J. Ramirez ${ }^{4}$, J. Londono ${ }^{1} .{ }^{1}$ Grupo de investigación Espondiloartropatias, Universidad de La Sabana-Hospital Militar Central, Chía, Colombia; ${ }^{2}$ Hospital General de México, Ciudad de México, Mexico; ${ }^{3}$ Universidad del Norte, Barranquilla; ${ }^{4}$ Asociación Colombiana de Reumatología, Bogotá, Colombia

Background: Functional capacity is an important indicator of quality of life that is affected in different pathologies and is susceptible to intervention in early stages once it is recognised. In rheumatic diseases, functional limitation has a great impact that is evidenced by multiple degrees of long-term disability.

Objectives: To evaluate the functional capacity in different rheumatic diseases by $\mathrm{HAQ}$ (Health Assessment Questionnaire) instrument.

Methods: In the context of the prevalence study of rheumatic disease in Colombia, the assessment of functional capacity was measured by using the HAQ score, where functional limitation is scored in a range from 0 to 3 points according to the severity of limitation. The major functional limitation is scored 3 and not limitation 0 .

A total of 4020 individuals answered the questionnaire.

Results: Patients with rheumatic diseases $(n=2274)$ reported a greater degree of limitation compared with disease-free people $(n=1104)$ or non-rheumatic patients $(n=642) \quad(p<0,001)$. Especially patients with rheumatoid arthritis $(R A)$ had the worst score $(0.88 \pm 0,72)$ compared to $0.06 \pm 0,22$ and $0.01 \pm 0,14$ of the population with non-rheumatic and healthy population, respectively $(p<0.001)$. The HAQ score in the remaining diseases was $0,67(S D \pm 0,62)$ for systemic lupus erythematosus (SLE), followed by patients with osteoarthrosis $(\mathrm{OA}) 0,59(\mathrm{SD} \pm 0,58)$, fibromyalgia (FM) 0,56 (SD $\pm 0,57)$ and spondylarthritis $(S p A)$ 0,52 (SD $\pm 0,43)$. Abstract AB1299-Figure 1

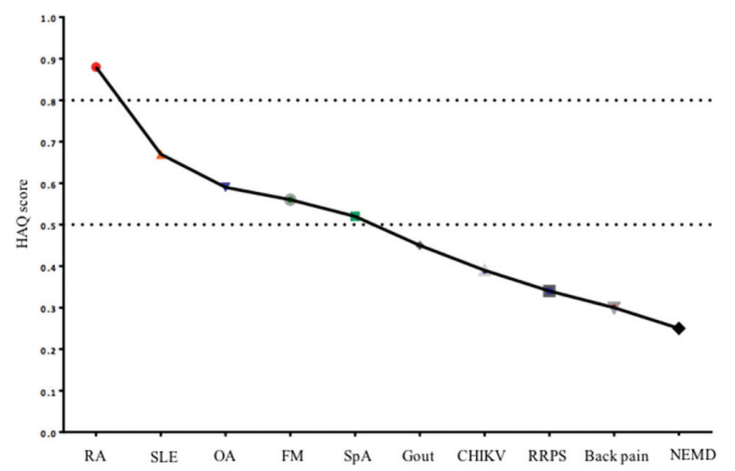

Abstract AB1299 - Figure 1. Functional capacity of patients with rheumatic diseases
Functional capacity evaluated by $\mathrm{HAQ}$, the points represent the mean of the instrument. * RA: Rheumatoid Arthritis; SLE: Systemic Lupus Erythematosus; OA: Osteoarthritis; FM: Fibromyalgia; SpA: Spondyloarthritis; CHIKV: Chikungunya fever; RRPS: Rheumatic Regional Pain Syndromes (Rotator cuff tendinopathy, shoulder bicipital tendinopathy, lateral and medial medial epicondylalgia, Quervain's tendinopathy, carpal tunnel syndrome, Dupuytren's contracture, trochanteric syndrome, anserine bursitis, achilles tendonopathy, plantar talalgia); NEMD: non-specific musculoskeletal disease.

Conclusions: In comparison with disease-free population and non-rheumatic patients, the rheumatic patients had a lower functional capacity measured by HAQ. Patients with RA had more disability followed by patients with SLE and OA. Disclosure of Interest: None declared DOI: 10.1136/annrheumdis-2018-eular.4336

\section{AB1300 COMORBIDITIES IN PATIENTS WITH RHEUMATIC DISEASES IN COLOMBIA}

F.M. Cuervo ${ }^{1}$, A. Santos ${ }^{1}$, E.L. Saldarriaga ${ }^{1}$, J.C. Rueda ${ }^{1}$, I. Angarita ${ }^{1}$, I. Peláez ${ }^{2}$, E. Forero ${ }^{3}$, J. Ramirez ${ }^{4}$, C. Toro ${ }^{4}$, J. Londono ${ }^{1} .{ }^{1}$ Grupo de investigación Espondiloartropatias, Universidad de La Sabana-Hospital Militar Central, Chía, Colombia; ${ }^{2}$ Hospital General de México, Ciudad de México, Mexico; ${ }^{3}$ Universidad del Norte, Barranquilla; ${ }^{4}$ Asociación Colombiana de Reumatología, Bogotá, Colombia

Background: Patients with systemic autoimmune conditions often develop concomitant disease contributing to a higher mortality than in the general population. An early diagnosis and treatment is fundamental to improve the life expectancy of this population.

Objectives: The objective of this study was to describe the frequency of comorbidities in patients with rheumatic diseases.

Methods: Based on data from the population studied under the COPCORD strategy, in the prevalence of rheumatic disease in Colombia, the frequency of nonrheumatic diseases in patients with rheumatic diseases was described in 6 cities of Colombia (Bogotá, Medellín, Cali, Barranquilla, Bucaramanga and Cúcuta).

Results: From a total of 4020 individuals, 2274 rheumatic patients were identified.

Sixty nine percent of the Colombian patients with rheumatic disease $(n=1571)$ had some comorbidity. The most frequent was hypertension (HBP) in $20,95 \%$ $(n=330)$, followed by migraine $19,11 \%(n=300)$ and venous insufficiency $17,69 \%$ $(n=278)$. Seventeen percent had any mental disorders, of which, anxiety and depression were the most common $(n=273)$.

Other comorbidities like obesity $(8,1 \%)$, diabetes $(5,85 \%)$, heart disease $(5,79 \%)$ and cerebrovascular disease $(1,99 \%)$ were less common among rheumatic patients. The frequency of cancer was low $1.48 \%(n=23)$. Abstract AB1300 Figure 1

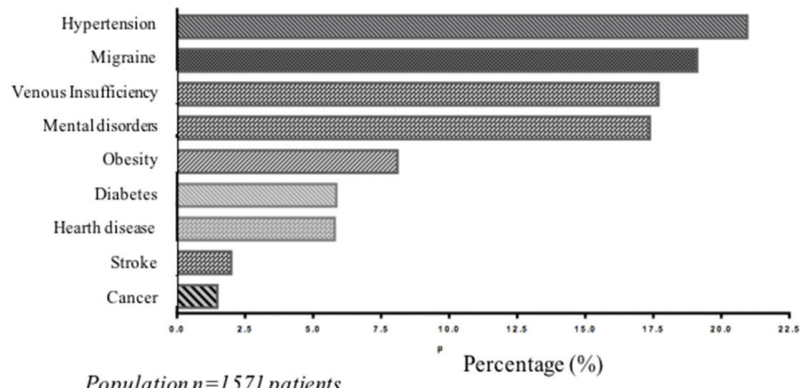

Abstract AB1300 - Figure 1. Most frequent comorbidities in rheumatic patients

Conclusions: Hypertension is the most common comorbidity in patients with rheumatic diseases in Colombia. Screening and diagnosis in early stages of HBP is important, since it is the main modifiable cardiovascular risk factor. The goals of pharmacological and non-pharmacological treatment are essential to reduce the risk of coronary heart disease, stroke and end-stage renal disease. Additionally, migraine is the second most frequent disease that affects the patient's quality of life. And venous insufficiency should be taken into account by primary care physicians in order to assure a complete health care assessment.

Disclosure of Interest: None declared

DOI: 10.1136/annrheumdis-2018-eular.4350 